\title{
Quantitation of lymphocyte transformation using radioactive iododeoxyuridine
}

\author{
A. W. CRAIG, J. V. GARRETT, AND S. M. JACKSON \\ From the Christie Hospital and Holt Radium Institute, Manchester
}

SYNOPSIS A method is described of measuring the response of human lymphocytes to phytohaem-용 agglutinin stimulation using iododeoxyuridine labelled with the gamma-emitting isotope ${ }^{125}$. N The results indicate useful clinical applications.

Measurements of the response of lymphocytes to a stimulus in vitro such as phytohaemagglutinin (PHA) were originally made on a morphological basis. This meant either counting the percentage of cells which have been transformed into blast cells, or determining the mitotic index of the cultured lymphocytes. Difficulties arise in these methods because of subjective errors and problems in obtaining representative samples. Interest has therefore turned to the development of isotope techniques for quantitating lymphocyte transformation. The possibility of incorporating a suitable radioactive precursor into the nucleic acid of the transformed cells has led to experiments in which labelled thymidine has been added as a tracer for DNA (Aisenberg, 1965; Michalowski, 1963; Sell, Rowe, and Gell, 1965; Tormey and Mueller, 1965) and radioactive uridine has also been used to label RNA (Cooper and Rubin, 1965; Mueller and Le Mahieu, 1966). There is good evidence from these experiments that the degree of transformation of lymphocytes can be correlated with the uptake of isotope into the nucleic acid. The counting procedures for the $\beta$-emitting isotopes employed require careful control and are in themselves time-consuming. Because of the ease of measuring $\gamma$-emitting isotopes we chose a metabolic analogue of thymidine, iododeoxyuridine (IUdR), labelled with a $\gamma$-emitting isotope of iodine, ${ }^{125} \mathrm{I}$, half-life 60 days. Previous studies have shown that labelled IUdR can function as a specific label for DNA, with reutilization of the radioactivity reduced to a minimum (Fox and Prusoff, 1965).

\section{METHOD}

Freshly taken defibrinated human blood was used and

Received for publication 16 December 1968. lymphocytes were separated using a methyl cellulose-iron mixture (Coulson and Chalmers, 1967). These prepara- $D$ tions regularly contained over $95 \%$ lymphocytes. In an

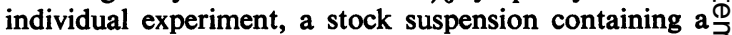
known number of cells was prepared in TC 199 medium음 with $20 \%$ of autologous serum-methyl cellulose mixture. $\stackrel{\Phi}{-}$ Two millilitre aliquots of this suspension were placed in $\vec{\bullet}$ screwcapped tubes and incubated at $37^{\circ} \mathrm{C}$ after the addition of $0.05 \mathrm{ml}$ of a PHA preparation (containing $500 \mu \mathrm{g}$. of PHA). At daily intervals, beginning two days after the addition of PHA, three samples, were incubated for three hours with ${ }^{125}$ I-IUdR (or ${ }^{3} \mathrm{H}-\mathrm{TdR}$ ) solution. Routinely $4 \times 10^{-7} \mathrm{mM}$ of the labelled DNA precursor was added.» This had been found to lie within the range of dosage $\mathbb{D}$ where there was no adverse effect on cell uptake. After $\stackrel{2}{\Rightarrow}$ incubation the samples were centrifuged for 10 minuteso음 at $1,800 \mathrm{rpm}$ and the supernatant was discarded. The cells $\Xi$ were washed with $3 \mathrm{ml}$ saline, centrifuged for a further? 10 minutes at $1,800 \mathrm{rpm}$, and the supernatant was again? discarded. Finally $2 \mathrm{ml}$ saline and $0.2 \mathrm{ml}$ calf serum (as carrier protein) were added to each sample and the sus-: pended cells sonicated.

Each sonicated sample was shaken vigorously with $0.15 \mathrm{ml}$ of saturated TCA solution and cooled in an ice bath for 10 minutes, centrifuged, and the precipitate suspended in ice-cold $5 \%$ TCA solution for 10 minutes.o Treatment with $5 \%$ TCA was repeated twice and the final precipitate was counted in a scintillation counter. When ${ }^{3} \mathrm{H}-\mathrm{TdR}$ was used the procedure involved an additional four successive extractions with hot TCA; each extraction $N_{0}$ was made by suspending the precipitate in hot $5 \%$ TCA and heating for five minutes in a boiling water bath. The tritium activity was measured by counting aliquots of the $5 \%$ TCA solution in a Triton X/toluene phosphor usingo a liquid scintillation counter (Fox, 1968).

It would be desirable to determine the actual number: of cells present at the time of incorporation of the radioactivity. However, we found that the clumping of cells in the PHA-treated culture makes it impossible to estimate them accurately. We have therefore presented the results? in terms of chemical uptake of the DNA precursor pero $10^{6}$ lymphocytes initially present. 

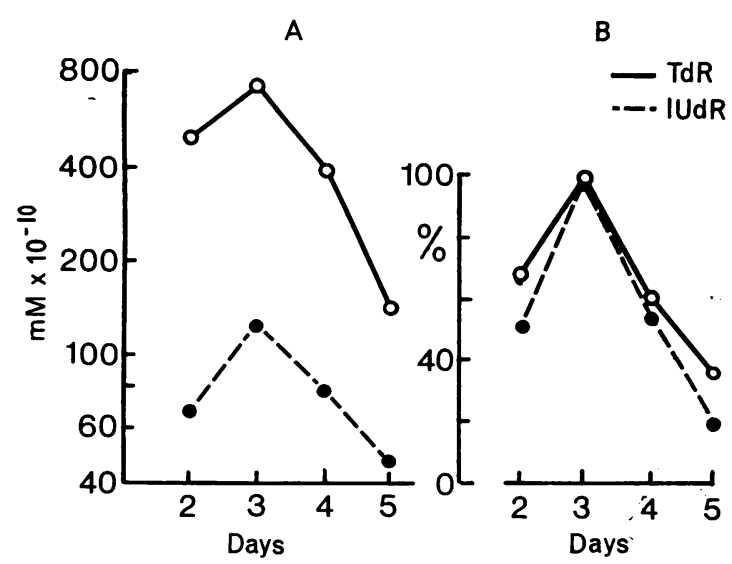

FIG. 1. The uptake of ${ }^{3} H-T d R$ or ${ }^{125} I-I U d R$ by PHAtreated human lymphocytes. Individual samples initially contained $1.125 \times 10^{8}$ lymphocytes and only one of the labelled DNA precursors was added. A Chemical uptake expressed as $\mathrm{mM} \times 10^{-10}$ per $10^{6}$ lymphocytes initially present; B percentage of maximum daily uptake.

\section{RESULTS}

A series of comparisons of the incorporation of ${ }^{3} \mathrm{H}-\mathrm{TdR}$ and ${ }^{125} \mathrm{I}-\mathrm{IU}$ dR were made. In Fig. 1, the uptake of labelled thymidine in a PHA-treated normal human lymphocyte preparation is compared with the uptake of radioactive IUdR in a separate series of samples using the same source of lymphocytes. In both series the same quantity of DNA precursor, $4 \times 10^{-7} \mathrm{mM}$, was added to each sample. It can be seen that a higher proportion of the thymidine is incorporated. However, if the relative uptake on successive days is compared (Fig. 1B), using the highest daily uptake as $100 \%$, a very similar pattern of incorporation is found with either thymidine of iododeoxyuridine. An analysis was made of the relative uptake of the thymidine and IUdR in another experiment where both precursors were added to each sample (Fig. 2). Again more thymidine was incorporated, but although timing for the maximum daily uptake was different, the
A

B

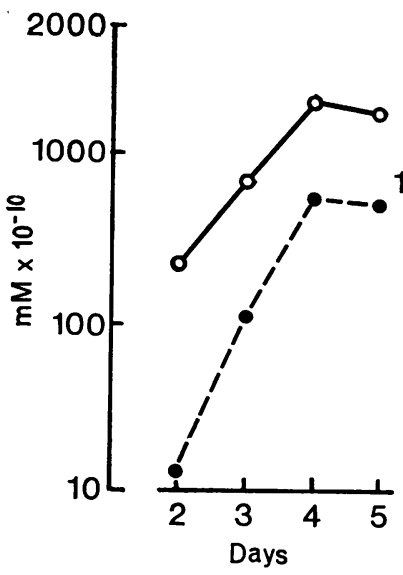



FIG. 2. The uptake of ${ }^{3} \mathrm{H}-\mathrm{TdR}$ or ${ }^{125} \mathrm{I}-\mathrm{IUdR}$ by PHAtreated human lymphocytes. Individual samples contained $0.38 \times 10^{8}$ lymphocytes and both labelled DNA precursors were added. A Chemical uptake expressed as $m M \times 10^{-10}$ per $10^{6}$ lymphocytes initially present; B percentage of maximum daily uptake.

relative uptake of the two labelled precursors was very similar (Fig. 2 B). From these results it would appear that ${ }^{125}$ I-IUdR can be used as an index of the response of the PHA-stimulated human lymphocytes. We are applying this method to quantitate the effect of PHA on lymphocytes obtained from patients during the clinical course of Hodgkin's disease and other allied conditions.

We wish to thank Dr S. Muldal and Dr M. E. Macauley for advice and help and Mrs K. A. Carter for technical assistance.

\section{REFERENCES}

Aisenberg, A. C. (1965). Nature (Lond.), 205, 1233.

Cooper, H. L., and Rubin, A. D. (1965). Blood, 25, 1014.

Coulson, A. S., and Chalmers, D. G. (1967). Immunology, 12, 417.

Fox, B. W. (1968). Int. J. appl. Radiat., 19, 717.

- and Prusoff, W. H. (1965). Cancer Res., 25, 234.

Michalowski, A. (1963). Exp. Cell. Res., 32, 609.

Mueller, G. C., and Le Mahieu, M. (1966). Biochim. biophys. Acta (Amst.), 114, 100.

Sell, S., Rowe, D. S., and Gell, P. G. H. (1965). J. exp. Med., 122, 823.

Tormey, D. C.. and Mueller, G. C. (1965). Blood, 26, 569. 